A. VIROSZTEK

\title{
VARIATIONAL METHOD FOR 1-D SPIN CHAINS
}

\section{Hungarian Academy of Sciences} CENTRAL RESEARCH INSTITUTE FOR PHYSICS 
KFKI-1984-125

\section{VARIATIONAL METHOD FOR 1-D SPIN CHAINS}

A. VIROSZTEK

Central Research Institute for Physics H-1525 Budapest 114, P.O.B.49, Hungary 


\section{ABSTRACT}

We report on a new variational method for determining the ground state energy of antiferromagnetic Heisenberg spin chains with nearest neighbour interaction. The method enables us to extrapolate to the exact energy and it is shown that the first few approximations give better results than other approximate methods.

\section{АННОТАЦИЯ}

Разработан новый вариационный подход, с помощью которого можно определить энергию основного состояния антиферромагнитной гейзенберговской спиновой цепи с учетом взаимодействия ближайших соседей. Разработанный подход пригоден и для определения точного значения энергии, пользуясь экстраполяцией; при этом учет нескольких первых цагов дает лучшие результаты, чем другие приближенные методы.

\section{KIVONAT}

Egy uj variációs módszert irunk le, melynek segitségével meghatározható az elsốszomszéd kölcsönhatást tartalmazó antiferromágneses Heisenberg-spinlánc alapállapoti energiája. A módszer alkalmas az egzakt energia extrapolációval történố kiszámitására, továbbá az elsô néhány közelités jobb eredményeket ad, mint más közelitó eljárások. 
The exact value for the ground state energy of the antiferromagnetic Heisenberg chain is known only for $\mathrm{S}=1 / 2$ spins (des Cloizeaux and Gaudin 1966). However, the Bethe-Ansatz (Bethe 1931) can't be applied for chains with spins larger than $1 / 2$. In these cases one has to perform approximate calculations. Recently quantum spin chains with $\mathrm{S}=1$ are widely investigated both experimentally (Kjems and Steiner 1978) and theoretically (Haldane 1983). The $\mathrm{S}=1$ magnetic chain $\mathrm{CsNiF}_{3}$ has been described by the following Hamiltonian:

$$
H=\sum_{j=1}^{N}\left[S_{j}^{x} S_{j+1}^{x}+S_{j}^{y} S_{j+1}^{y}+\rho S_{j}^{z} S_{j+1}^{z}+D\left(S_{j}^{z}\right)^{2}\right] ; N+1 \equiv 1
$$

where $S_{j}^{x}, S_{j}^{y}, S_{j}^{z}$ are the components of the spin operator on the j-th site, $\rho$ and $D$ are the exchange and the on-site anisotropy, respectively (for $\operatorname{CsNiF}_{3} \rho=-1$, and $D=0.38$ was used).

Our aim in this letter is to present a new variational method for calculating the ground state energy of the Hamiltonian (1). In ordex to describe the above system for $S>1 / 2$ various approximate methods have been used. One of them is the straightforward diagonalization of (1) for finite rings. Blöte (1978) computed the ground state energy per lattice site for rings containing $\mathrm{N}$ spins. The diagonalization can be performed numerically for small $\mathrm{N}$ providing a set of energy values $\mathrm{E}(\mathrm{N})$ which can be used to extrapolate to the exact value in the thermodynamic limit: $E(N) \rightarrow E(\infty)=E_{\text {exact }}$ when $N \rightarrow \infty$. 
In this case one uses finite systems to obtain information about the infinite system.

Another group of methods is based on a simple mean-field theory (Mead and Papanicolaou 1982). Sólyom and Ziman (1984) applied this theory for the Hamiltonian (1) supposing that the $\mathrm{N}-\mathrm{spin}$ wavefunction is the direct product of one-spin wavefunctions:

$$
\psi^{(N)}\left(S_{1}, S_{2}, \ldots, S_{N}\right)=\prod_{i=1}^{N} \otimes \psi\left(S_{i}\right)
$$

where the one-spin wavefunction $\psi(5)=a(1)|1\rangle+a(0)|0\rangle+a(-1)|-1\rangle$. Here the kets represent the three possible state of one spin with $s=1$ and $a(1), a(0), a(-1)$ are variational parameters. Using the (2) variational trial function one can calculate the energy per lattice site as a function of the variational parameters:

$$
E(a(1), a(0), a(-1))=\frac{1}{N} \frac{\left\langle\psi^{(N)}|H| \Psi^{(N)}\right\rangle}{\left\langle\psi^{(N)} \mid \psi^{(N)}\right\rangle}
$$

The r.h.s. of. (3) doesn't depend on $\mathrm{N}$ and minimization with respect to $a(1), a(0), a(-1)$ yields the ground state energy in the mean-field approximation. Although this calculation refers to an infinite system it doesn't include any correlations between spins.

There are two possible way to improve this theory. The first was done by Sólyom (1984) and is based on the following idea. Let us construct a wavefunction which is the product of 
k-spin wavefunctions instead of one-spin wavefunctions $(k=2,3, \ldots):$

$$
\psi^{(N)}\left(S_{1}, S_{2}, \ldots, S_{N}\right)=\prod_{j=0}^{N / k} \otimes \psi\left(S_{j k+1}, S_{j k+2}, \ldots, S_{j k+k}\right)
$$

In this case the chain of length $\mathrm{N}$ is divided into "clusters" containing $\mathrm{k}$ spins and the cluster-wavefunction has the form e.g. for $k=2$ :

$$
\psi\left(S_{1}, S_{2}\right)=a(1,1)|1,1\rangle+a(1,0)|1,0\rangle+\ldots+a(-1,-1)|-1,-1\rangle
$$

After calculating the expectation value of the energy per lattice site in the (4) state and minimizing with respect to the variational parameters $a(1,1), \ldots, a(-1,-1)$ one obtains a set of approximate values for the ground state energy $\mathrm{E}(\mathrm{k})$ depending on the cluster size k. Apparently $E(\infty)=E_{\text {exact }}$, so the $E(k)$ set can be used for extrapolation as well. This method (hereafter referred to as spin-cluster method) includes correlations between spins belonging to the same cluster (the bonds inside a cluster are treated correctly). However, there is no correlation between spins of different clusters and the energy contribution of bonds connecting the neighbouring clusters are averaged in a mean-field like manner.

Now we present the second possible way to improve the simple mean-field theory. The basic idea is that the energy contributions of the nearest-neighbour exchange Hamiltonian are connected with the bonds instead of sites. In order to take into account all of the bonds with the same accuracy 
let us divide the chain of length $\mathrm{N}$ into clusters containing $\mathrm{k}$ bonds instead of $\mathrm{k}$ spins (Fig. 1). In this way each bond belongs to a well defined cluster (hereafter often referred to as bond-cluster) and the neighbouring clusters are coupled by the common spin.

The appropriate wavefunction will have the form:

$$
|\psi\rangle=\sum_{\underline{n}} c(\underline{n})|\underline{n}\rangle
$$

where $|\underline{n}\rangle=\left|n_{1}, \ldots, n_{N}\right\rangle \quad\left(n_{i}=1,0,-1\right\rangle$ are basic vectors and

$$
\begin{gathered}
c(\underline{n})=c\left(n_{1}, \ldots, n_{N}\right)=a\left(n_{1}, n_{2}, \ldots, n_{k+1}\right) a\left(n_{k+1}, n_{k+2}, \ldots, n_{2 k+1}\right) \ldots \\
\ldots a\left(n_{j k+1}, \ldots, n_{(j+1) k+1}\right) \ldots a\left(n_{N-k+1}, \ldots, n_{N}, n_{1}\right)
\end{gathered}
$$

Here $\boldsymbol{\alpha}\left(\boldsymbol{\sigma}_{1}, \boldsymbol{\sigma}_{2}, \ldots, \boldsymbol{\sigma}_{k}, \boldsymbol{\sigma}_{k+1}\right)$ is an element of a three dimensional coefficient tensor which has $k+1$ indices, and belongs to the bond-cluster with bond configuration determined by the spin configuration $\boldsymbol{\sigma}_{1}, \ldots, \boldsymbol{\sigma}_{k+1}$.

The expectation value of the energy per lattice site in the state given by (6) and (7) is:

$$
E=\frac{1}{N} \frac{\langle\psi|H| \psi\rangle}{\langle\psi \mid \psi\rangle}
$$

This expression has to be minimized numerically with respect to the elements of above mentioned coefficient tensor. If we increase the size of the bond-cluster (k) we obtain a set of ground state energy approximations $\mathrm{E}(\mathrm{k})$. It is clear that 
$\lim _{k \rightarrow \infty} E(k)=E_{\text {exact }}$ so we have the possibility for extrapolation again.

It is worth-while to look into certain details of the calculation. In order to evaluate (8) let us begin with the norm of the trial function:

$$
\begin{gathered}
\langle\psi \mid \psi\rangle=\sum_{\underline{n}}|c(\underline{n})|^{2}=\sum_{n_{1}, \ldots, n_{N}}\left|a\left(n_{1}, \ldots, n_{k+1}\right)\right|^{2}\left|a\left(n_{k+1}, \ldots, n_{2 k+1}\right)\right|^{2} \ldots \\
\ldots\left|a\left(n_{j k+1}, \ldots, n_{(j+1) k+1}\right)\right|^{2} \ldots\left|a\left(n_{N-k+1}, \ldots, n_{1}\right)\right|^{2}
\end{gathered}
$$

If we define the $3 \times 3$ nonnegative matrix

$$
T_{\sigma \sigma^{\prime}}=\sum_{\sigma_{2}, \ldots, \sigma_{k}}\left|a\left(\sigma_{1} \sigma_{2}, \ldots, \sigma_{k}, \sigma^{\prime}\right)\right|^{2}
$$

the norm can be expressed as

$$
\langle\psi \mid \psi\rangle=S_{p}\left(T^{N / k}\right)
$$

The nominator of (8) can be calculated straightforwardly in similar manner and we obtain that the energy per lattice site has the form

$$
E=\frac{1}{k} \frac{S_{p}\left(T^{N / k-3} Q\right)}{S_{p}\left(T^{N / k}\right)}
$$

where $Q$ is a $3 \times 3$ matrix and its elements are complicated but well defined functions of the variational and anisotropy parameters (the $\mathrm{T}$ matrix depends only on the variational parameters, see (10)). Let us suppose that $\mathrm{T}$ can be diagonalized by 
similarity transformation i.e. $U^{-4} T U=\Lambda$ and $\Lambda$ is diagonal with elements $\lambda_{0}>\lambda_{1}>\lambda_{2}$. It is easy to show that in this case (12) can be rewritten in the form:

$$
E=\frac{1}{k} \lambda_{0}^{-3} \frac{\widetilde{Q}_{00}+\left(\lambda_{1} / \lambda_{0}\right)^{N / k-3} \widetilde{Q}_{19}+\left(\lambda_{2} / \lambda_{0}\right)^{N / k-3} \widetilde{Q}_{22}}{1+\left(\lambda_{1} / \lambda_{0}\right)^{N / k}+\left(\lambda_{2} / \lambda_{0}\right)^{N / k}}
$$

Here $\widetilde{Q}_{i j}=\left(U^{-1} Q U\right)_{i j}$ and now we are able to perform the $N \rightarrow \infty$ limit for any given $k$ :

$$
E=\frac{1}{k} \lambda_{0}^{-3} \widetilde{Q}_{00}
$$

The above expression is a function of the cluster size $k$, the anizotropy parameters $S$ and $D$ and the variational parameters. After numerical minimization we obtain a set of energies $E(k)$ for any given $\rho$ and $D$ values and the extrapolation to the exact value can be performed from these data.

In order to check our method we have carried out the calculation for $S=1 / 2$ where the exact results are known. The ground state energy approximations in the isotropic antiferromagnetic point $(\rho=1)$ are given in Table 1 in the bond-cluster row up to $k=5$. These values are shown in Fig. 2 as a function of $1 / k$ as well. It can be seen that $E(k)-E(\infty) \sim 1 / k$ for large k. First we have performed the $1 / \mathrm{k}$ fit for neighbouring points only. Then the $1 / \mathrm{k}$ fit was applied again for the new set of approximations. The result of the extrapolation and the exact value $(1 / 4-\ln 2)$ are also given in Table 1 (the discrepancy between the extrapolated and exact result is $\sim 0.045 \%$ ). 
In Table 2 we have given our results for $S=1$ in the isotropic antiferromagnetic point $(\rho=1, D=0)$ and in the XY $\operatorname{limit}(\rho=D=0)$. In the $\rho=1, D=0$ point Blöte (1978) extrapolated from finite rings to the value -1.400 .

We have compared our approximate values to the data given by finite-ring and spin-cluster calculations in Table 1 . It can be seen that the discrepancy between the approximate and exact values are 10-5 times larger for the finite-ring method and 2-3 times larger for the spin-cluster method than for our bond-cluster method in the case of small $(k=2, \ldots, 5)$ clusters. In other words the relative discrepancy ranges from $\sim 70 \%$ to $\sim 10 \%$ for the finite-ring calculations, from $\sim 15 \%$ to $\sim 9 \%$ for the spin-cluster method and from $\sim 6 \%$ to $\sim 3 \%$ for the bond-cluster method.

In conclusion the above described bond-cluster method takes into account the contribution of each bond with the same accuracy and due to the common spin of neighbouring bond-clusters there is correlation between spins belonging to different clusters as well. (It can be shown by straightforward calculation, that $\left\langle S_{i}^{2} S_{j}^{2}\right\rangle \sim \exp \left\{-\frac{|c-j|}{f}\right\}$ where $\xi=\ln ^{-1} \frac{\lambda_{0}}{\lambda_{1}}$ and the $\lambda^{\prime} \mathrm{s}$ are the eigenvalues of the $T$ matrix). Due to these advantages the variational procedure gives considerably better approximations for small clusters (in practice only small sizes can be treated numerically) than the other methods mentioned here. The bond-cluster picture might be useful for other 1-D lattice systems with nearest neighbour interaction. 
It must be added that certain informations concerning the phase diagram can be obtained by examining the final values of the variational parameters. A ferromagnetic - XY phase boundary passing through the $\rho=-1 \quad(D=0)$ point was found for both $\mathrm{S}=1 / 2$ and $\mathrm{S}=1$ and for each value of $\mathrm{k}$. There was a possibility to detect an antiferromagnetic - XY phase boundary through the appearence of the sublattice magnetization which is zero in the $X Y$ phase and finite in the antiferromagnetic phase. But, unfortunately we couldn't find any way to make distinction between the $X Y$ and the singlet phase while increasing the on-site anisotropy D. Therefore the detailed study of the phase diagram wasn't possible.

Stimulating discussions with J. Sólyom are gratefully acknowledged. 
REFERENCES

Bethe H A 1931 z. Phys. 71205

Blöte H W J 1978 Physica $\underline{93 B} 93$

des Cloizeaux J and Gaudin M 1966 J. Math. Phys. 71384

Haldane F D M 1983 Phys. Rev. Lett. 50 1.153

Kjems J K and Steiner M 1978. Phys. Rev. Lett. 411137

Mead L R and Papanicolaou N 1982 Phys. Rev. B26 1416

Sólyom J 1984 to be published

Sólyom J and Ziman T A L 1984 preprint KFKI 
Table 1

Approximate energy values for

$\mathrm{S}=1 / 2$ at the $\mathrm{\rho}=1$ (and $\mathrm{D}=0$ ) isotropic antiferromagnetic point using different methods

k

12

3.

4

5 extrapol. exact

$\begin{array}{lllllllll}\text { finite ring } & - & -0.75 & -0.25 & -0.5 & -0.3736 & \\ \text { spin-cluster } & -0.25 & -0.3750 & -0.3761 & -0.4040 & -0.4031 & & \\ \text { bond-cluster } & -0.4078 & -0.4155 & -0.4217 & -0.4255 & -0.4282 & -0.4429 & -0.4431\end{array}$


Table 2

Approximate and extrapolated energy values for $\mathrm{S}=1$ at two points on the $\mathrm{D}=\mathrm{O}$ line using the bond-cluster method

k

$\rho=1$

$\rho=0$
1

2

3

4

Extrapol

$-1.3158$

$-1.0796$

$-1.0887$
$-1.3438$

$-1.3520$

$-1.3922$

$-1.0944$
$-1.0981$ 


\section{FIGURE CAPTIONS}

Fig. 1. Division of the chain of length $\mathrm{N}$ into bond-clusters of size $\mathrm{k}$.

Fig. 2. Energy approximations for $S=1 / 2$ at the isotropic antiferromagnetic point as a function of $1 / \mathrm{k}$. 

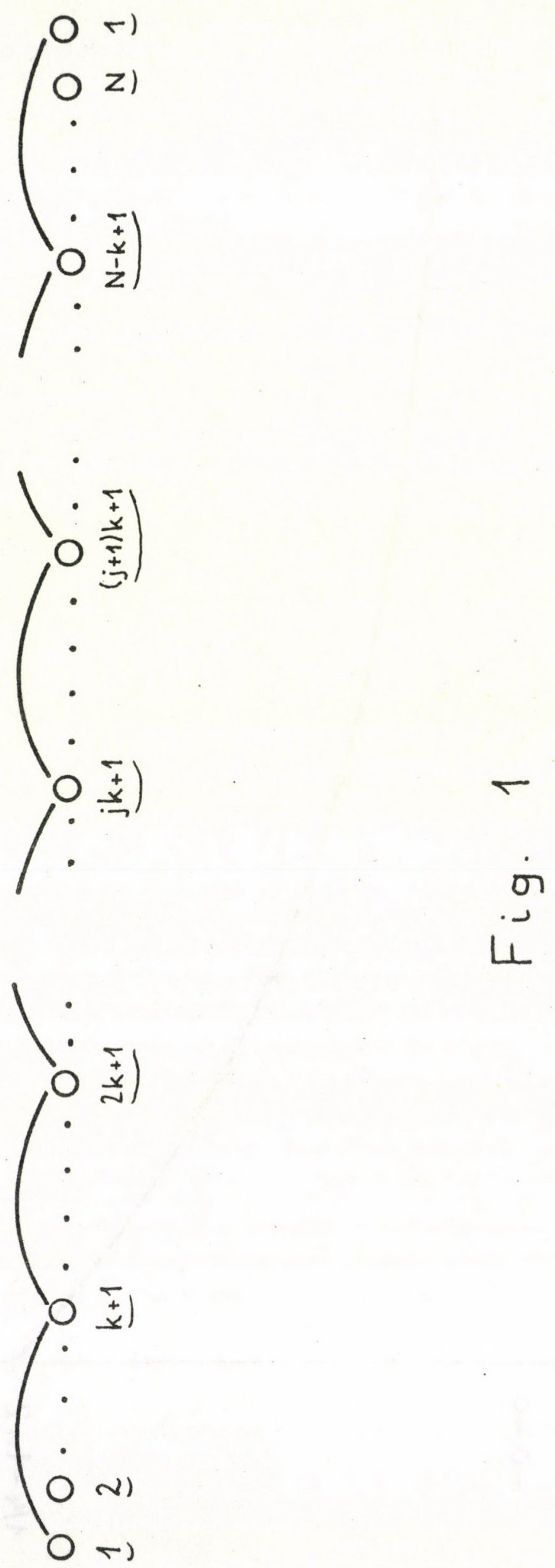


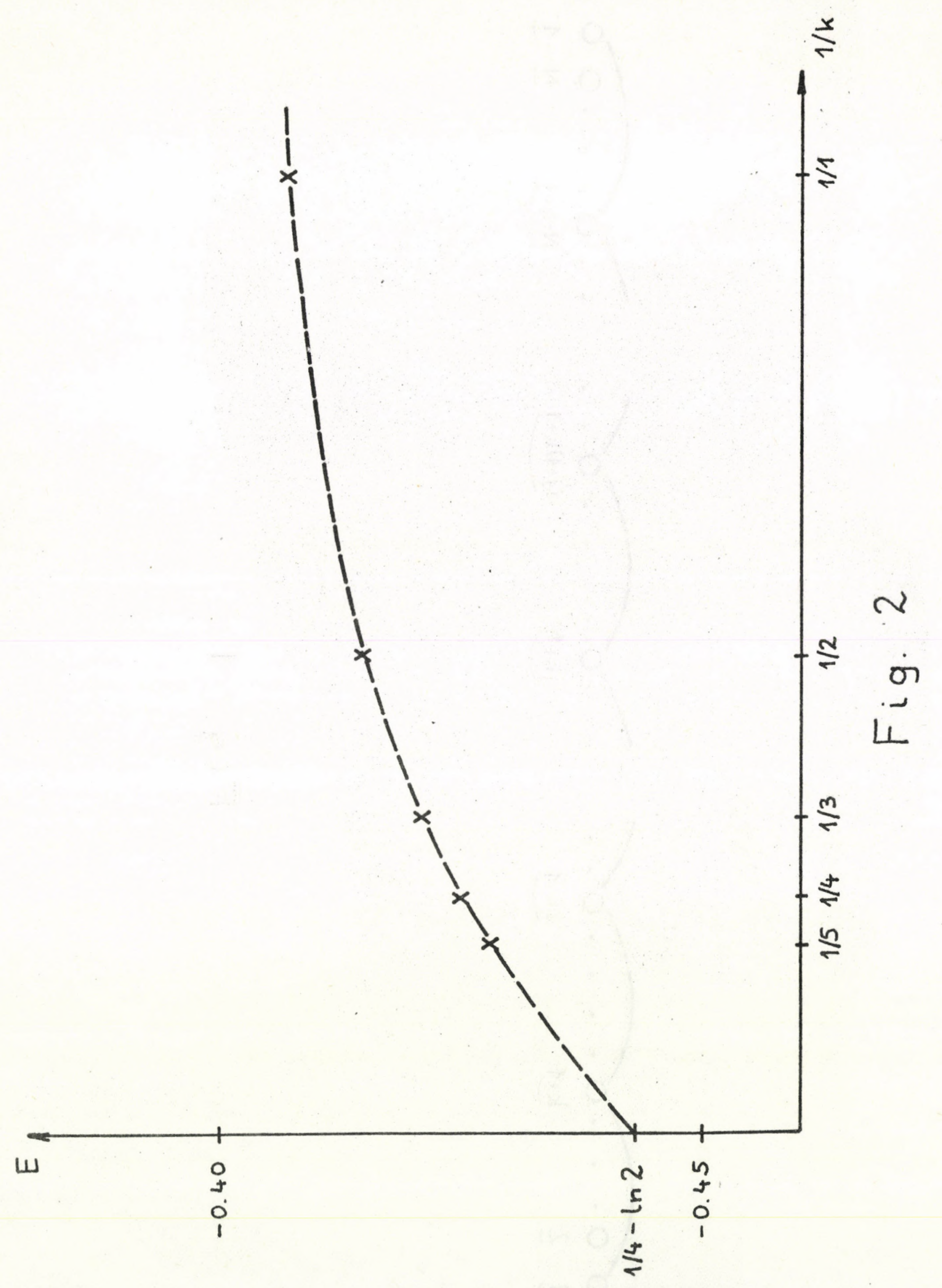





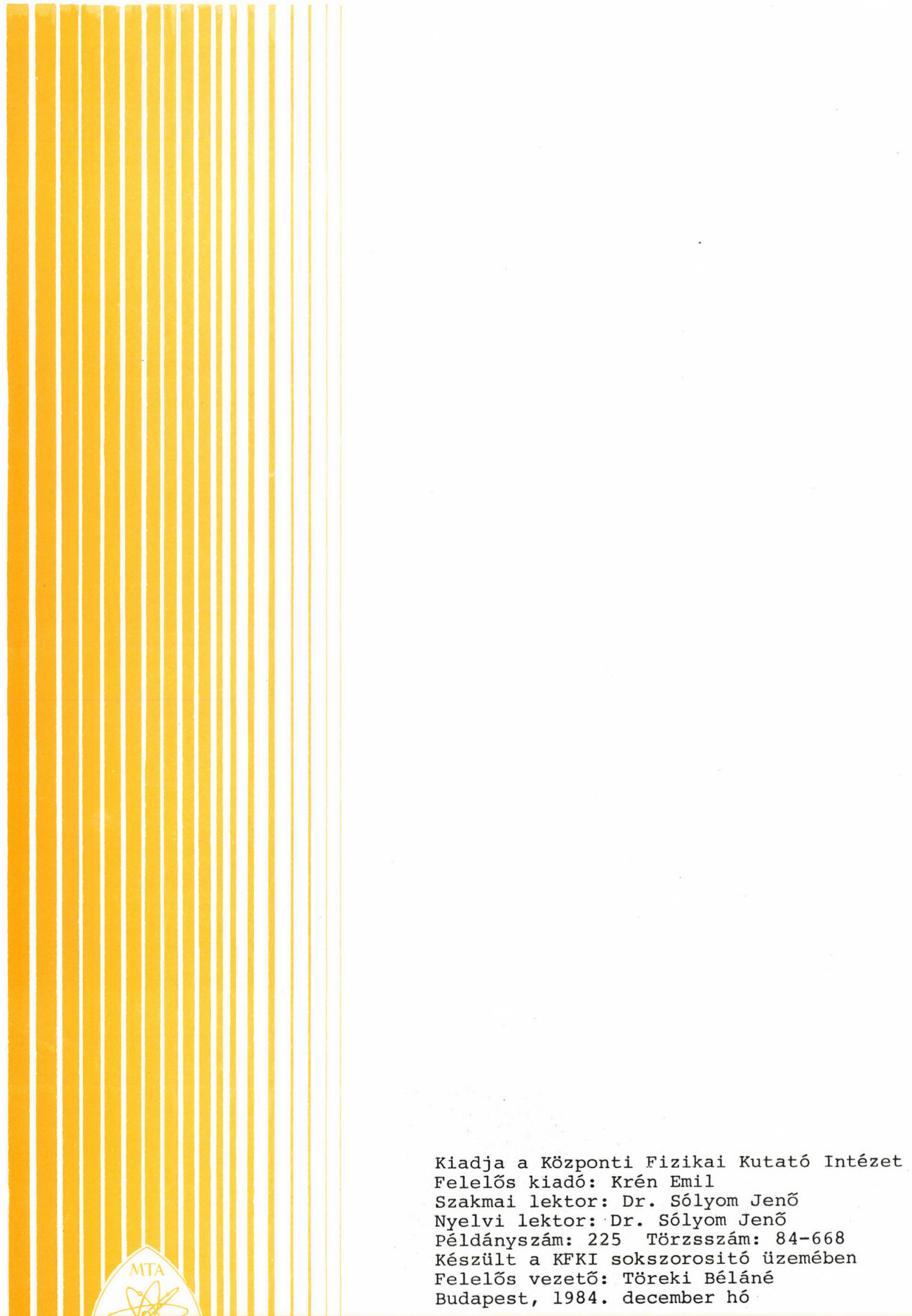

